Original Article

\title{
DESIGN AND IN VITRO EVALUATION OF FLOATING DRUG DELIVERY SYSTEM OF GLIPIZIDE USING COMBINATION OF NATURAL MUCILAGES AND SYNTHETIC POLYMERS
}

\section{DALAPATHI GUGULOTHU*, SURAJ KUMAR CHOUDHARY}

Department of Pharmaceutics, Balaji Institute of Pharmaceutical Sciences, Laknepally (V), Narsampet (M), Warangal Rural(D), Telangana State, 506331, India

*Email: dalugugulothu@gmail.com

Received: 30 Mar 2021, Revised and Accepted: 08 May 2021

\begin{abstract}
Objective: The objective of the study is to explore polysaccharide mucilages of Colocasia esculenta (CE), and Fenugreek (FG) as buoyancy enhancing agents, and mucoadhesive agents by developing gastroretentive floating tablets of Glipizide.

Methods: Glipizide loaded floating tablets were developed with CE, and FG alone and in combination of Guar gum (GG), and Hydroxypropyl methylcellulose (HPMC) K4M using direct compression technique. The developed formulations have been subjected to evaluation of in vitro buoyancy study, in vitro drug release study ( $\mathrm{pH}$ 1.2), and in vitro bioadhesiveness study. Therefore, the final optimized formulation was subjected to Fourier Transform Infrared Spectroscopy (FTIR), Differential scanning calorimetry (DSC), and X-ray powder diffraction (XRD) study.

Results: The results of the buoyancy study for formulation F1, F2, and F5 revealed that the instant floating lag time, floating time duration of $1 \mathrm{~h}$, and exhibited 100\% drug release in $4 \mathrm{~h}$. Therefore, the formulations developed with GG (F3), and HPMC K4M (F4) have been exhibited slow floating lag time, prolonged floating duration and drug released up to $100 \%$ in $12 \mathrm{~h}$, while; formulations F6, F7, F8, and F9 have been exhibited shortest floating lag time, longest floating time duration, the best drug released up to $12 \mathrm{~h}$, and better in vitro bioadhesiveness properties. Furthermore, F7 exhibited good bioadhesive property as compared to F6, F8-F9. The results of the FTIR, DSC, and XRD study for F7 revealed that the presence of functional groups and amorphous.
\end{abstract}

Conclusion: Owing to the anticipated properties like biocompatibility, biodegradability, swelling ability, and cost-effectiveness of CE; it could be the potential macromolecule for the replacement of synthetic polymers.

Keywords: Buoyant tablets, Glipizide, In vitro bioadhesive test, Polysaccharide mucilages, Sustained drug release

(C) 2021 The Authors. Published by Innovare Academic Sciences Pvt Ltd. This is an open access article under the CC BY license (https://creativecommons.org/licenses/by/4.0/)

DOI: https://dx.doi.org/10.22159/ijpps.2021v13i7.41644. Journal homepage: https://innovareacademics.in/journals/index.php/ijpps.

\section{INTRODUCTION}

Natural powdered extracts are acquired from vegetable sources with high molecular weight uronic acid and sugar units [1]. They are novel hydrocolloids with a broad range of applications in the pharmaceutical era, such as emulsifying agents, gelling agents, suspending agents, thickening agents, binders, matrix-forming agents, disintegrants, and mucoadhesive agents [2-9]. At present numerous scientists have explored natural mucilages in the development of novel drug delivery systems. For instance, Reddy et al. 2010, developed sustained release matrix tablets of Diltiazem using Gum karaya and Gum kondagogu [10], Prajapati et al. 2014 developed sustained release mucoadhesive macromolecule of aceclofenac using Locust bean gum [11], Dwivedi et al. 2017 prepared sustained release matrix-tablets of metformin with Cassia tora mucilage [12], Hadad et al. 2018 developed electrospunnanofibers using flax seed mucilage [13], Liang et al. 2015, prepared gastric floating controlled-release tablets using Konjac Glucomannan [14], Rimi et al. 2005 prepared nasal drug delivery systems of diazepam using Trigonella Foenum Graecum [15], Maithi et al. 2010 developed hydrogel beads of Glipizide using Locust bean gumand floating microparticles of metformin using glycinemax [16], metroxylonsagu and Plantagoovate by Pandey et al. 2016 [17]. Gastroretentive drug delivery system (GRDDS) can prolong the retention of drugs in the gastrointestinal region for several hours and increase the sustained release of drugs, those which are having an absorption window in a particular region of GIT after oral administration [18]. The enhanced gastric retention improves bioavailability, and increases the solubility of drugs due to its extensive advantages [19]. Presently, numerous types of approaches have been reported for development of GRDDS which include; floating systems, bioadhesive systems, hydrodynamically balanced systems, swelling, and expanding systems to enhance the gastric residence time [20, 21]. However, these dosage forms are very effective, when the fluid level in the stomach is sufficiently high. Though, the buoyancy of the tablet may be hindered at pylorus in empty conditions [22]. Owing to this, it can be restrained by developing the formulation and it may be required to attach the mucous membrane of the stomach wall.

Mucoadhesionhave has been employed for targeted drug delivery by the addition of mucoadhesive polymers with active pharmaceutical ingredients for the development of pharmaceutical formulations. Mucoadhesive materials are hydrophilic macromolecules containing assorted hydrogen bond forming groups [23]. $C E$, and $F G$ powdered extracts were previously explored as versatile pharmaceutical excipients [15]. These are hydrophilic, biodegradable, biocompatible, nontoxic, amusing resources, and have been widely employed as additives in the development of drug delivery systems $[24,25]$. Glipizide is an oral hypoglycemic agent, which is generally prescribed drug for the prevention of non-insulin-dependent diabetes mellitus (NIDDM) [26], through exciting insulin secretion from the pancreatic islets of Langerhans and several other extra pancreatic effects, such as enhancing sensitivity to insulin and decreasing the hepatic glucose production [27]. Owing to the short biological half-life $(3.4 \pm 0.7 \mathrm{~h})$ of Glipizide, it is administered 2 or 3 times with doses of $2.5-10 \mathrm{mg}$ per day. It is practically insoluble in water and highly permeable (Biopharmaceutical Classification System, Class II). Moreover, Glipizide is mostly absorbed from the upper parts of the gastrointestinal tract. The dosage forms with bioadhesive, and floating properties can sustain the drug release and increases the buoyancy of the tablet in the stomach as well as improves the oral bioavailability of Glipizide [28-30].

In the present study, naturally conquering $\mathrm{CE}$ and FG mucilage powders have been extracted and used as the Mucoadhesive, and the 
buoyancy promoting agents in Glipizide-loaded floating tablets preparation [31]. The main objective of the present study is to develop mucoadhesive, swellable, floating GRDDS by using CE, FG, $\mathrm{GG}$, and HPMC K4M alone and in combination to improve gastric retention by lowering the floating lag time, and enhancing the floating duration with sustained drug release profiles and mucoadhesive property of Glipizide loaded GRDDS. Glipizide loaded floating tablets optimized based on buoyancy properties, in vitro drug release studies, and in vitro mucoadhesive studies.

\section{MATERIALS AND METHODS}

\section{Materials}

Glipizide was purchased from Yarrow Chemicals Private Limited, Mumbai, India. HPMC K4M ${ }^{\circledR}, \mathrm{GG}$, Sodium bicarbonate, Citric acid, Magnesium stearate ${ }^{\circledR}$, Talc (Purified), and Microcrystalline Cellulose $\left(\right.$ MCC $\left.^{\circledR}\right)$ were purchased from Qualikems Fine Chem Pvt. Ltd. Vadodara, Gujarat, India. CE and FG were purchased from the local market, Narsampet, Warangal, India. All other purified chemicals and solvents were of analytical grade.

\author{
Methods \\ Preparation of Glipizide loaded floating tablets by direct \\ compression technique
}

Glipizide-loaded floating tablets prepared by using CE, FG, GG, and HPMC K4M ${ }^{\circledR}$ solitary and in combination. These polymers form a gel-like matrix after contact with the gastrointestinal fluid to attain the low density of formulation as compared to that of GI Fluid (GI fluid density 1) [32]. Citric acid and Sodium bicarbonate were used as effervescent agents to produce carbon dioxide and preserve the buoyancy of a tablet [32]. Talc, and $\mathrm{MCC}^{\circledR}$ were used as glidant, and diluent respectively. All the above powders except Magnesium stearate ${ }^{\circledR}$ were sieved through a sieve of mesh No\# 60. The components of the formulations mixed in a cubic mixer for $15 \mathrm{~min}$. Magnesium stearate ${ }^{\circledR}$ was added into the formulation blend a lubricant, and mixed for another $5 \mathrm{~min}$. Followed by the blend was subjected to tablet preparation by direct compression technique (Karnavati double rotary tablet press) [33]. The developed $100 \mathrm{mg}$ tablets contained $10 \mathrm{mg}$ of Glipizide. Formulation of Glipizide loaded sustained release mucoadhesive floating tablets revealed in table 1.

Table 1: Formulation of glipizide loaded mucoadhesive sustained release floating tablets: formulations from F1-F9

\begin{tabular}{|c|c|c|c|c|c|c|c|c|c|c|}
\hline S. No. & Ingredients (mg) & F1 & F2 & F3 & F4 & F5 & F6 & F7 & F8 & F9 \\
\hline 1 & Glipizide & 10 & 10 & 10 & 10 & 10 & 10 & 10 & 10 & 10 \\
\hline 2 & $\mathrm{CE}$ & 40 & -- & -- & -- & 20 & 20 & 20 & -- & -- \\
\hline 3 & FG & -- & 40 & -- & -- & 20 & -- & -- & 20 & 20 \\
\hline 4 & GG & -- & -- & 40 & -- & -- & 20 & -- & 20 & -- \\
\hline 5 & HPMC K4M & -- & -- & -- & 40 & -- & -- & 20 & -- & 20 \\
\hline 6 & Citric acid & 10 & 10 & 10 & 10 & 10 & 10 & 10 & 10 & 10 \\
\hline 7 & $\mathrm{NaHCO}_{3}$ & 10 & 10 & 10 & 10 & 10 & 10 & 10 & 10 & 10 \\
\hline 8 & MCC & 25 & 25 & 25 & 25 & 25 & 25 & 25 & 25 & 25 \\
\hline 9 & Talc & 02 & 02 & 02 & 02 & 02 & 02 & 02 & 02 & 02 \\
\hline 10 & Magnesium Stearate & 03 & 03 & 03 & 03 & 03 & 03 & 03 & 03 & 03 \\
\hline \multicolumn{2}{|c|}{ Total weight of tablet (mg) } & 100 & 100 & 100 & 100 & 100 & 100 & 100 & 100 & 100 \\
\hline
\end{tabular}

GG: Guar Gum; CE: Colocasia esculenta; FG: Fenugreek; HPMC: Hydroxy propyl methylcellulose; MCC: Microcrystalline Cellulose; NaHCO3: Sodium bicarbonate.

\section{Evaluation of post-compression parameters}

Glipizide loaded sustained release mucoadhesive floating tablets have been subjected to evaluate the thickness, weight variation, hardness, friability, and drug content uniformity [34].

\section{Weight variation test}

The weight variation test has been performed by selecting 20 tablets randomly from each formulation and weighed using Mettler Toledo Electronic Balance $(0.1 \mathrm{mg}$ ) (Mettler Toledo India Private Limited, Mumbai, India). The results were calculated and reported as mean average weight \pm standard deviation (SD).

\section{Thickness test}

The thickness of the tablets performed by selecting 10 tablets randomly from each formulation and it was the thickness of the tablet was measured by using digital Vernier Caliper. The results reported as mean thickness \pm SD.

\section{Hardness test}

To study the hardness test of Glipizide loaded floating tablets, 6 tablets from each formulation have been selected and the tablet breaking force was recorded using Monsanto hardness tester. The hardness results reported as mean \pm SD.

\section{Friability study}

20 pre-weighed tablets from each formulation have been selected and transferred into Roche friabilator plastic chamber. Then the friabilator has been operated at $25 \mathrm{rpm}$, dropping the tablets at distance of 6 inches in each revolution, and then it was operated for $4 \mathrm{~min}$. This test was used to determine the effect of shock and abrasion in a plastic chamber with revolution. The tablets re- weighed after removal of dusted fines and the percentage friability was calculated using the following formula.

$$
\% \text { Frability }=\text { IW }-\frac{\mathrm{FW}}{\mathrm{IW}} * 100------(1)
$$

Where IW: Initial weight; FW: Final weight

\section{Drug content uniformity}

10 tablets from each formulation have been selected randomly and crushed into a fine powder. The quantity of powder which equivalent to $10 \mathrm{mg}$ of Glipizide was taken and transferred to $100 \mathrm{ml}$ volumetric flask and dissolved in $0.1 \mathrm{NHCl}(\mathrm{pH} 1.2)$ solution. Followed by measured the absorbance at $270 \mathrm{~nm}\left(\lambda_{\max }\right)$ using UV spectrophotometer (PG Instruments Limited, United Kingdom). The drug content in each formulation was calculated by using a standard calibration curve [31]. This study was performed in triplicate and the average \% drug content in each formulation was reported as mean $\pm S \mathrm{~S}$.

\section{The In vitro buoyancy test}

This study can be performed by using USP Tablet disintegration test apparatus II containing $900 \mathrm{ml}$ of $0.1 \mathrm{~N} \mathrm{HCl}(\mathrm{pH} \mathrm{1.2)}$ medium. By using this study, Floating lag time, (FLT) (time required for the tablet to reach the surface of the medium from the bottom) and floating duration or buoyancy (tablet which persistently floats in medium) can be calculated [32].

\section{The Swelling index study (SI)}

The SI was performed by selecting 6 tablets from each formulation randomly and was weighed $\left(\mathrm{W}_{0}\right)$ separately and kept individually in a glass beaker containing $200 \mathrm{ml}$ of $0.1 \mathrm{~N} \mathrm{HCl}$ and incubated at $37^{\circ} \mathrm{C} \pm 1{ }^{\circ} \mathrm{C}$. Then swollen floating tablets taken from the beaker and the excess surface liquid was removed and weighed for every $1 \mathrm{~h}$ 
time interval $\left(\mathrm{W}_{\mathrm{t}}\right)$. The swelling index $(\mathrm{SI})$ was calculated by using the following formula [35].

$$
\mathrm{SI}=\mathrm{Wt}-\frac{\mathrm{Wo}_{0}}{\mathrm{~W}_{\mathrm{o}}} * 100-\cdots---(2)
$$

Where $W_{t}$ is the weight of tablet at time $t, W_{0}$ is the initial weight of the tablet

\section{In vitro drug release studies}

The in vitro drug release study of Glipizide loaded floating tablets performed by using USP Type II instrument (Paddle Type). The $500 \mathrm{ml}$ of $0.1 \mathrm{~N} \mathrm{HCl}$ dissolution media was maintained at $37 \pm 0.5^{\circ} \mathrm{C}$ at $50 \mathrm{rpm}$ for 12h. A $5 \mathrm{ml}$ aliquot sample was withdrawn from the dissolution test apparatus at various time intervals and the same volume of media was substituted with a fresh dissolution medium. The samples have been filtered through a $0.45 \mu \mathrm{m}$ membrane filter and suitably diluted. The absorbance of these solutions was measured at $\lambda_{\max } 270 \mathrm{~nm}$ by using a spectrophotometer [24] and this was performed in triplicate.

\section{Kinetic analysis of release data}

The kinetic analysis of drug release data has been subjected to various kinetic models like first-order kinetics, Zero-order kinetics, Higuchi and Korsmeyer-Peppas models using DDSolver an add-in-program for Microsoft excel sheet. The correlation co-efficient $\left(\mathrm{R}^{2}\right)$ has been subjected to determine the best fit of the drug release mechanism.

\section{In vitro mucoadhesion study}

The in vitro mucoadhesion force was evaluated by the EZ-X500N Shimadzu texture analyzer (Singapore) using TRAPEZIUM X software. Fresh sheep gastric mucosa has been collected from a local slaughterhouse and used within $2 \mathrm{~h}$ of slaughtering. The mucosal membrane was cleaned with distilled water and consequently with phosphate buffer $\mathrm{pH} 6.8$ then fixed in between two plates followed by placed in a beaker. The tablet is carefully attached to a $10-\mathrm{mm}$ cylindrical Jig with an adhesive tape. Then Jig moved down towards mucosa at a constant speed at $15 \mathrm{~mm} / \mathrm{S}$ until a predetermined compressive force of $0.5 \mathrm{~N}$ withholding time $180 \mathrm{~s}$ and load cell $500 \mathrm{~g}$ was achieved. The Jig was subsequently moved up with a speed at $15 \mathrm{~mm} / \mathrm{S}$ to a distance of 15 $\mathrm{mm}$. Followed by mucoadhesive strength and mucoadhesive detachment force was recorded. 3 tablets randomly selected from each formulation and employed on fresh mucosa [36, 37].

\section{FTIR study}

The FTIR spectrum of the drug, CE, HPMC, and final formulations were recorded by using Bruker, Alpha FTIR Spectrophotometer for preparing sample pellets using $\mathrm{KBr}$ disk method. The scanning range was $400-4000 \mathrm{~cm}^{-1}$. This study was used to determine the interaction and change of functional groups in between drug, powder extracts, polymer, and final formulation [38].

\section{DSC study}

To confirm the further drug excipients interaction and thermal behavior property DSC was performed (Hitachi High-Tech SciencesModel DSC7020, USA). DSC was performed for drug, CE, HPMC, and F7. The $5 \mathrm{mg}$ of the drug, HPMC, and final formulation were sealed in an empty preweighed aluminium pan, and scanned in the temperature range of $25-250^{\circ} \mathrm{C}$ under an atmospheric nitrogen rate of $10^{\circ} \mathrm{C} / \mathrm{min}$, followed by a cooling cycle back to a rate of $20^{\circ} \mathrm{C}$. A blank aluminium pan was used a reference [39].

\section{XRD study}

XRD patterns of Glipizide, CE, HPMC, and final optimized formulation were analyzed by using the X-ray-diffractometer ( $\mathrm{P}$ Analytical, The Netherlands). The powder sample has been sealed in rectangular aluminium cells, illuminated by using the $\mathrm{Cu}-\mathrm{Ka}$ radiation $(\mathrm{k}=1.54056 \mathrm{~A})$ at $45 \mathrm{kV}$ and $30 \mathrm{~mA}$. The samples were scanned between diffraction angles of 6 to $80^{\circ}$. The scan step of 0.008 was used and the $\mathrm{d}$ well time was $10 \mathrm{~s}$. A nickel filter was used to reduce the $\mathrm{Kb}$ contribution to the X-ray signal. The'd' spacing was computed according to Bragg's law of diffraction [39].

\section{RESULTS}

\section{Formulation of glipizide floating tablets}

In the present exploration, mucoadhesive, floating, and sustainedrelease tablets of Glipizide developed by using $\mathrm{CE}(\mathrm{F} 1), \mathrm{FG}(\mathrm{F} 2), \mathrm{GG}(3)$, HPMC K4M(F4) alone and in combination with $\mathrm{CE}+\mathrm{FG}(\mathrm{F} 5)$, $\mathrm{CE}+\mathrm{GG}(\mathrm{F} 6), \quad \mathrm{CE}+\mathrm{HPMC} \quad \mathrm{K} 4 \mathrm{M}(\mathrm{F} 7), \quad \mathrm{FG}+\mathrm{GG}(\mathrm{F} 8)$ and $\mathrm{FG}+\mathrm{HPMC}$ K4M(F9). Additionally, Citric acid ${ }^{\circledR}$ and Sodium bicarbonate ${ }^{\circledR}$ have been used as gas generating agents, whereas, Talc ${ }^{\circledR}$, MCC $^{\circledR}$ Magnesium stearate ${ }^{\circledR}$ have been used as glidant, bulking agents, and lubricants respectively. The formulations have been demonstrated in table $1[40]$.

Table 2: Characterization of Glipizide loaded mucoadhesive sustained release floating tablets.

\begin{tabular}{|c|c|c|c|c|}
\hline Formulations & Thickness (mm) & \%Weight Variation & Hardness $\left(\mathrm{kg} / \mathrm{cm}^{2}\right)$ & \%Friability \\
\hline F1 & $03.7 \pm 0.4$ & $99 \pm 3.4$ & $04.9 \pm 0.52$ & $0.94 \pm 0.06$ \\
\hline F2 & $03.6 \pm 0.5$ & $99 \pm 1.0$ & $04.8 \pm 0.12$ & $0.9 \pm 0.07$ \\
\hline F3 & $03.5 \pm 0.5$ & $101 \pm 2.5$ & $04.7 \pm 0.35$ & $0.9 \pm 0.05$ \\
\hline F4 & $03.5 \pm 0.4$ & $99 \pm 1.2$ & $05.2 \pm 0.64$ & $0.7 \pm 0.07$ \\
\hline F5 & $03.5 \pm 0.2$ & $101 \pm 2.3$ & $05.00 \pm 0.94$ & $0.83 \pm 0.04$ \\
\hline F6 & $03.6 \pm 0.5$ & $98 \pm 2.1$ & $04.4 \pm 0.36$ & $0.99 \pm 0.06$ \\
\hline F7 & $03.7 \pm 0.5$ & $101 \pm 1.4$ & $05.12 \pm 0.38$ & $0.91 \pm 0.04$ \\
\hline F8 & $03.7 \pm 0.4$ & $99 \pm 1.2$ & $04.6 \pm 0.45$ & $0.56 \pm 0.08$ \\
\hline F9 & $03.7 \pm 0.4$ & $100 \pm 1.5$ & $04.5 \pm 0.35$ & $0.77 \pm 0.06$ \\
\hline
\end{tabular}

The data is expressed as mean \pm SD, (Thickness, $n=6$ ), (Weight Variation, $n=10)$, (Hardness=3), (Friability=20)

Table 3: Drug content, Buoyancy log time, and Total floating time results of Glipizide loaded mucoadhesive sustained release floating tablets

\begin{tabular}{llll}
\hline Formulations & \% drug content & Buoyancy lag time (s) & Total floating time (h) \\
\hline F1 & $100.52 \pm 0.50$ & $30 \pm 05$ & $1.0 \pm 0.20$ \\
F2 & $99.48 \pm 0.50$ & $34 \pm 06$ & $1.0 \pm 0.30$ \\
F3 & $102.07 \pm 1.5$ & $564 \pm 54$ & $16 \pm 0.50$ \\
F4 & $101.56 \pm 2.0$ & $41 \pm 09$ & $20 \pm 0.85$ \\
F5 & $102.07 \pm 2.50$ & $42 \pm 07$ & $1.0 \pm 0.37$ \\
F6 & $100.00 \pm 1.30$ & $220 \pm 36$ & $20 \pm 1.20$ \\
F7 & $101.04 \pm 0.55$ & $353 \pm 35$ & $20 \pm 0.65$ \\
F8 & $101.04 \pm 1.25$ & $330 \pm 12$ & $18 \pm 1.50$ \\
F9 & $101.04 \pm 0.14$ & $291 \pm 12$ & $18 \pm 0.50$ \\
\hline
\end{tabular}

The data is expressed as mean \pm SD, (Percent drug content, $n=10$ ) (Buoyancy lag time $(s), n=3)$, (Total floating time, $n=3$ ) 


\section{Physiochemical evaluation}

The developed formulations (F1-F9) were subjected to thickness, weight variation, hardness, friability, percent drug content, and the in vitro buoyancy studies, and the results expressed in table $2-3$. The thicknesses of the tablets found to be $3 \mathrm{~mm}$ to $4 \mathrm{~mm}$ and the weight variation test results exhibited in the range of $98-101 \%$ and within acceptable limit. The hardness of the formulations F1-F3, F5-F8 was found to be in the range of $4-5 \mathrm{~kg} / \mathrm{cm}^{2}$ (approx.), whereas formulations F4 and F9 exhibited in the range of $5-5.5 \mathrm{~kg} / \mathrm{cm}^{2}$ (approx.). Furthermore, the results of the friability test results found to be $<1 \%$ for all formulations and were within the limits and acceptable. The percent drug content uniformity of formulations F1-F9 exhibited in the range of $99-102 \%$ (table 3 ).

\section{The in vitro buoyancy test}

The results of the in vitro buoyancy study was expressed in table 3 . Glipizide-loaded floating tablet formulations developed with FG, CE and $\mathrm{CE}+\mathrm{FG}$ instantaneously floated to the surface of media and disappeared within $1 \mathrm{~h}$. It is indicated that the formulations F1-F2 and F5 having a low density as compared to gastric fluid, although they may necessitate some additional matrix forming agents for maintaining prolonged floating duration in the stomach [41]. FLT of F3 and F4 found to be $564 \pm 54 \mathrm{~s}$ and $60 \pm 12 \mathrm{~s}$ respectively; it may be attributed to the strong hydrogel layer which was formed around the tablet layer. Whereas floating duration time was $16 \mathrm{~h}$ for F3, it is indicated that the $\mathrm{CO}_{2}$ was released from the gel matrix of the formulation. While the buoyant duration for formulation F4 was 20 h. It might be attributed to the low viscosity of HPMC K4M. Therefore, the buoyancy duration time for F6 and F7 was $20 \mathrm{~h}$. whereas; the FLT and buoyancy duration time for formulation F8 and F9 was $630 \pm 12 s, 291 \pm 12 \mathrm{~s}$ and $18 \mathrm{~h}$ respectively.

\section{Swelling index study}

The results of the swelling studies are expressed in table 4 and the F1 to F9 formulations have been shown the very good swelling properties. Furthermore, these results overlapped with the results of the in vitro buoyancy studies (floating duration). Also, the formulations from F6-F9 ensued in a very low viscous gel layer and encouraged the water to penetrate into the tablet layer, therefore SI was increased. Furthermore, formulation F3 exhibited moderate SI. It might be ascribed to the formation of a gel layer around the tablet core which was thick and it prevented the penetration of media into the tablet core [42].

Table 4: Swelling studies (\% swelling index) of formulations from F1-F9

\begin{tabular}{|c|c|c|c|c|c|c|c|c|c|}
\hline \multicolumn{10}{|c|}{ Formulations } \\
\hline Time (h) & F1 & F2 & F3 & F4 & F5 & F6 & F7 & F8 & F9 \\
\hline 1 & $181 \pm 11$ & $134 \pm 08$ & $165 \pm 09$ & $134 \pm 08$ & $189 \pm 09$ & $198 \pm 10$ & $166 \pm 08$ & $172 \pm 08$ & $180 \pm 07$ \\
\hline 2 & $264 \pm 13$ & $233 \pm 10$ & $171 \pm 07$ & $233 \pm 10$ & $223 \pm 11$ & $252 \pm 11$ & $205 \pm 11$ & $193 \pm 07$ & $199 \pm 09$ \\
\hline 3 & $313 \pm 16$ & $241 \pm 13$ & $199 \pm 08$ & $241 \pm 13$ & $268 \pm 11$ & $292 \pm 14$ & $250 \pm 11$ & $225 \pm 11$ & $236 \pm 10$ \\
\hline 4 & $325 \pm 18$ & $273 \pm 12$ & $211 \pm 10$ & $273 \pm 12$ & $263 \pm 12$ & $300 \pm 12$ & $289 \pm 14$ & $267 \pm 10$ & $280 \pm 12$ \\
\hline 6 & $326 \pm 12$ & $294 \pm 14$ & $230 \pm 11$ & $294 \pm 14$ & $270 \pm 10$ & $332 \pm 10$ & $301 \pm 13$ & $290 \pm 10$ & $320 \pm 18$ \\
\hline 8 & $356 \pm 13$ & $325 \pm 10$ & $253 \pm 10$ & $325 \pm 10$ & $279 \pm 09$ & $356 \pm 09$ & $312 \pm 10$ & $320 \pm 15$ & $333 \pm 16$ \\
\hline 10 & $366 \pm 19$ & $354 \pm 10$ & $275 \pm 9$ & $354 \pm 10$ & $289 \pm 08$ & $366 \pm 12$ & $324 \pm 12$ & $332 \pm 13$ & $345 \pm 11$ \\
\hline 12 & $370 \pm 21$ & $366 \pm 17$ & $298 \pm 05$ & $366 \pm 17$ & $350 \pm 12$ & $378 \pm 10$ & $345 \pm 11$ & $369 \pm 18$ & $378 \pm 10$ \\
\hline
\end{tabular}

The data is expressed as mean $\pm \mathrm{SD}(\mathrm{n}=3)$
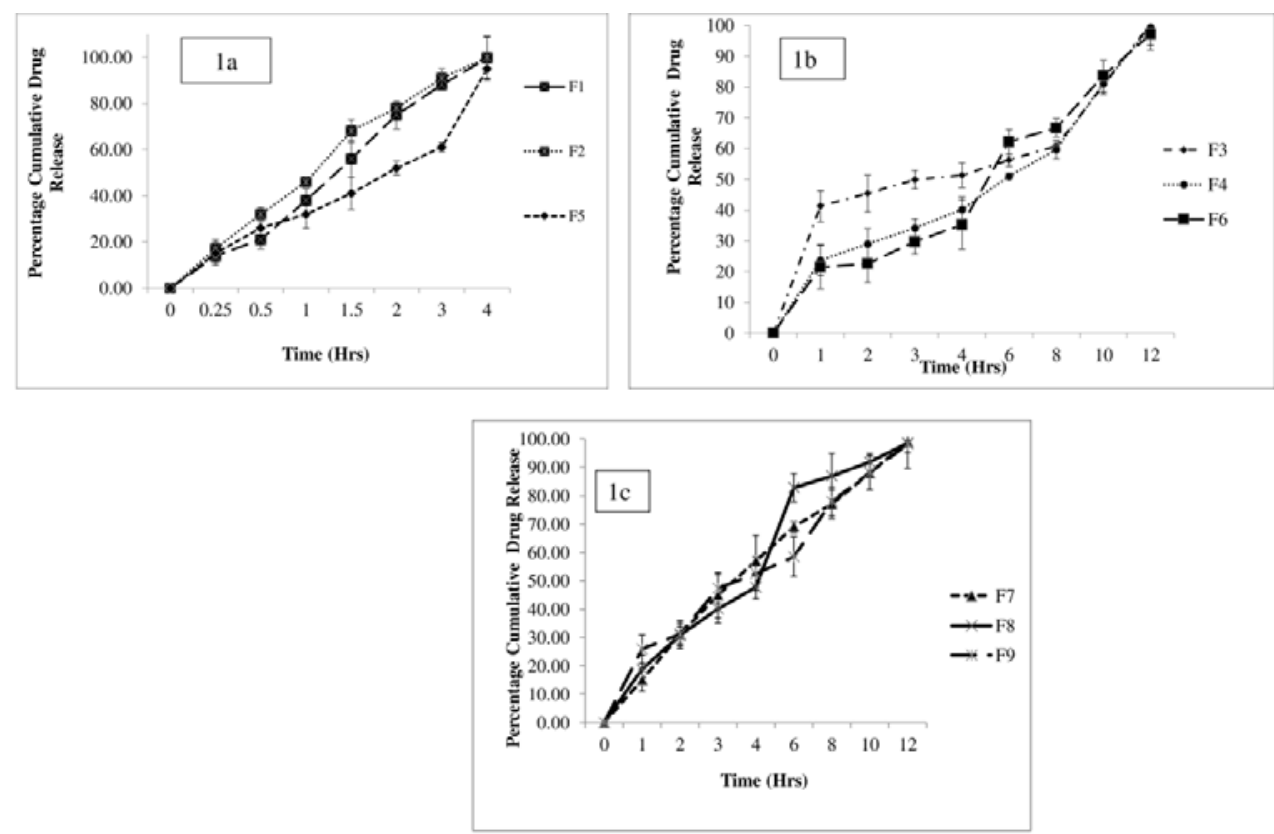

Fig. 1: The in vitro drug release profile of Glipizide loaded mucoadhesive sustained release floating tablets; 1a: Formulations from F1-F2, and F5; 1b. Formulations from F3-F4 and F6; 1c. F7-F9, The data is expressed as mean $\pm S D, n=3$

\section{In vitro drug release studies}

Glipizide-loaded floating tablets prepared with $\mathrm{CE}$ and FG and in a combination of CE+FG (F1-F2 and F5) demonstrated that $100 \%$ drug release in the period of $4 \mathrm{~h}$ (fig. 1a). The formulations developed with GG and HPMCK4M have confirmed that the prolonged floating duration along with drug release up to $12 \mathrm{~h}$ (F3-F4) (fig. 1b). It might be ascribed to the hydrophilic nature of GG, and HPMCK4M furthermore it could form a protective gel layer around the tablet core, thus arrests the drug release. The formulations developed with a combination of GG+CE (F6) (fig. 1b), HPMC K4M+CE (F7), GG+FG (F8), and HPMC K4M+FG (F9) (fig. 1c) exhibited drug release during 
12h. It is stated that GG and HPMCK4M could act as a drug release retardant in said formulations.

\section{Kinetic analysis of release data}

The results of the drug release mechanism, correlation coefficient $\left(\mathrm{R}^{2}\right)$ and " $n$ " was reported in table 5. The formulations from F1-F6 and F8 exhibited first-order release kinetics; whereas the formulations F7 and F9 have exhibited Higuchi's-model. Moreover, all the formulations subjected to the Peppas model, where the $\mathrm{R}$ value revealed, formulations were best fitted in the dissolution profile. The geometry of tablet is $\mathrm{n}=0.5$ means Fickian diffusion, whereas $0.5<\mathrm{n}<1.0$ NonFickian diffusion and $n=1.0$ Case II diffusion $[43,44]$.

Table 5: Drug release kinetics data of Glipizide loaded mucoadhesive sustained release floating tablets

\begin{tabular}{|c|c|c|c|c|c|c|c|}
\hline \multicolumn{8}{|l|}{$\mathbf{R}^{2}$} \\
\hline 1 & 2 & 3 & 4 & 5 & 6 & 7 & 8 \\
\hline F1 & 0.9010 & 0.7412 & 0.8417 & 0.9614 & 0.5697 & 2 & Diffusion and swelling controlled, Anomalous diffusion or non fickian-diffusion \\
\hline F2 & 0.9120 & 0.7120 & 0.8315 & 0.9844 & 0.5789 & 2 & Diffusion and swelling controlled, Anomalous diffusion or non fickian-diffusion \\
\hline F3 & 0.9545 & 0.9046 & 0.8245 & 0.9691 & 0.314 & 2 & Diffusion and Quasi-fickian \\
\hline F4 & 0.8854 & 0.7411 & 0.8240 & 0.9471 & 0.558 & 2 & Diffusion and swelling controlled, Anomalous diffusion or non fickian-diffusion \\
\hline F5 & 0.9501 & 0.98 & 0.9648 & 0.9616 & 0.565 & 2 & Diffusion and swelling controlled, Anomalous diffusion or non fickian-diffusion \\
\hline F6 & 0.9477 & 0.9808 & 0.9535 & 0.9301 & 0.674 & 2 & Diffusion and swelling controlled, Anomalous diffusion or non fickian-diffusion \\
\hline F7 & 0.9121 & 0.9795 & 0.9808 & 0.9759 & 0.552 & 4 & Diffusion and swelling controlled, Anomalous diffusion or non fickian-diffusion \\
\hline F8 & 0.8322 & 0.9116 & 0.9558 & 0.9752 & 0.702 & 2 & Diffusion and swelling controlled, Anomalous diffusion or non fickian-diffusion \\
\hline F9 & 0.6391 & 0.7791 & 0.832 & 0.8336 & 0.383 & 4 & Diffusion and Quasi-fickian \\
\hline
\end{tabular}

1. Formulation code; 2. First- order; 3. Zero-order.4. Higuchi's; 5. Korsmeyer-Peppas; 6. nvalue; 7. Drug release model; 8. Mechanism and indication of drug release

\section{In vitro bioadhesion measurement}

The in vitro bioadhesiveness test involves the characterization of the bioadhesiveness property of polymers that can adhere to the mucosal layer of the gastrointestinal tract. In this process, bioadhesion could be formed by the electrostatic interactionbonding between the polymer and mucous layer [45]. Usually, floating tablets could be buoyant in gastric fluid when the stomach is full of meal; however, the buoyancy of the tablet gets disturbed when the stomach get emptied and moves from the pyloric sphincter to the small intestine [45]. Hence, the buoyancy capability of floating tablets in the stomach restricted to only 3-4h. Although, bioadhesive tablets can be attached to the gastric mucosal wall at feed state and semi-liquid substances could be agitating under the effect of peristaltic movement [46]. The results of the in vitro bioadhesiveness strength (J) found to be $06.610 \pm 0.95,10.034 \pm 0.13$,
$06.84 \pm 1.02$, and $07.58 \pm 0.87$ respectively for F6-F7. Whereas, the results of the bioadhesive detachment force $\left(\mathrm{N} / \mathrm{m}^{2}\right)$ found to be $0.0648 \pm 0.0092,0.0984 \pm 0.210,0.0588 \pm 0.0872$, and $0.0943 \pm 0.763$ for F6-F9 respectively.

\section{FTIR study}

FTIR spectrum of drug and formulation (F7) did not show the major changes in the functional groups. It is indicating that the absence of drug and excipient interactions (fig. 2). Furthermore, the FTIR spectrum of formulations (F7) exhibited the presence of carboxyl groups and these groups can be the good binding site for the ions. Ghasemlou et al. 2011, reported that carboxyl groups could react with water and form an appropriate gel [43]. Moreover act as good bio adhesiveness agents by forming hydrogen bond between hydroxyl and carboxyl groups [43].
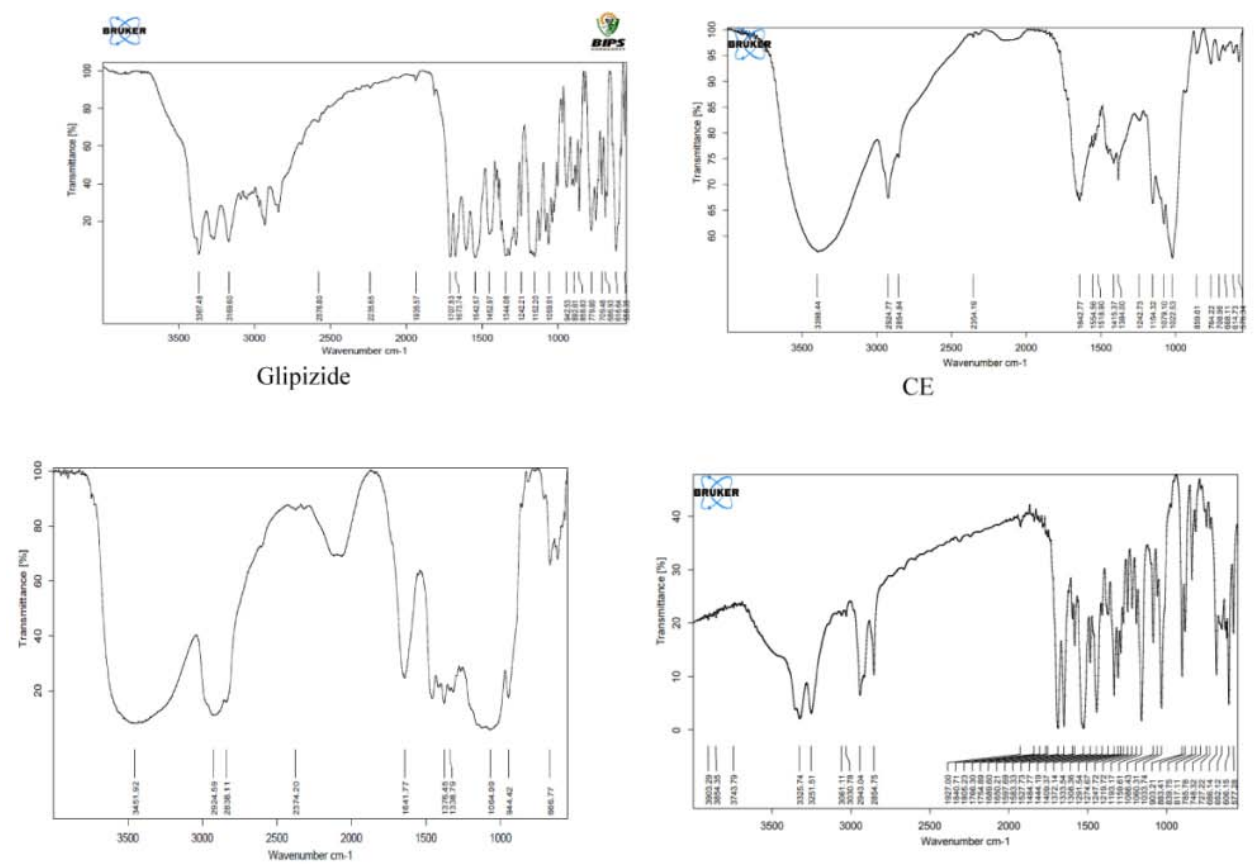

HPMCK 4 M

Fig. 2: FTIR spectrum of glipizide, CE, HPMC, and F7 


\section{DSC study}

DSC thermo grams of Glipizide, CE, HPMC, and F7 have been illustrated in fig. 3. The sharp endothermic peak of Glipizide observed at $217.5^{\circ} \mathrm{C}$. Where; the endothermic peak of CE and HPMC shown at $85.2^{\circ} \mathrm{C}$ and $58.2^{\circ} \mathrm{C}$ respectively. The formulation (F7) illustrated an endothermic peak at $53.4{ }^{\circ} \mathrm{C}$ (broad), $77.0^{\circ} \mathrm{C}$ (broad) $138.5^{\circ} \mathrm{C}$ (broad), $160.0^{\circ} \mathrm{C}$ (sharp) and they may be melting transition peaks of Sodium bicarbonate and Citric acid. Essa et al. 2015 stated that the related type peaks of bicarbonate and citric acid may not affect the physical state of the drug-loaded floating tablets [47]. Conversely, the sharp endothermic peak of Glipizide, CE, and HPMC disappeared in F7.

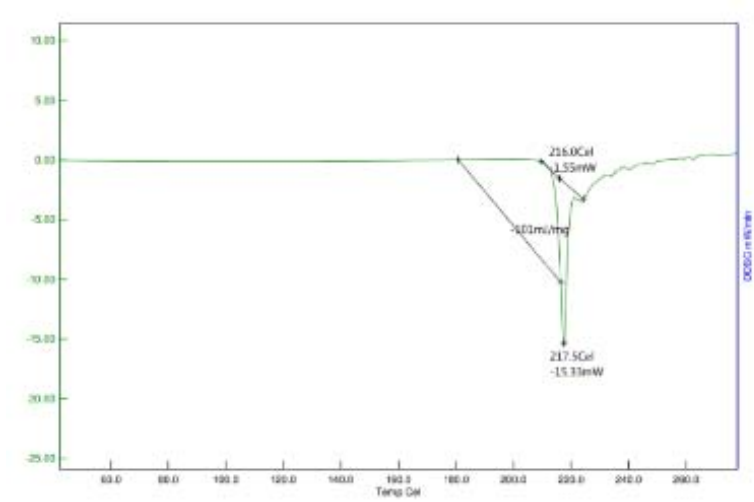

Glipizide

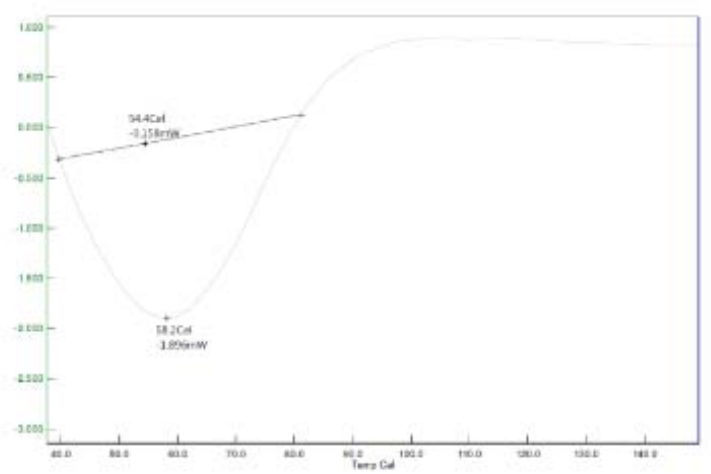

HPMC K4M

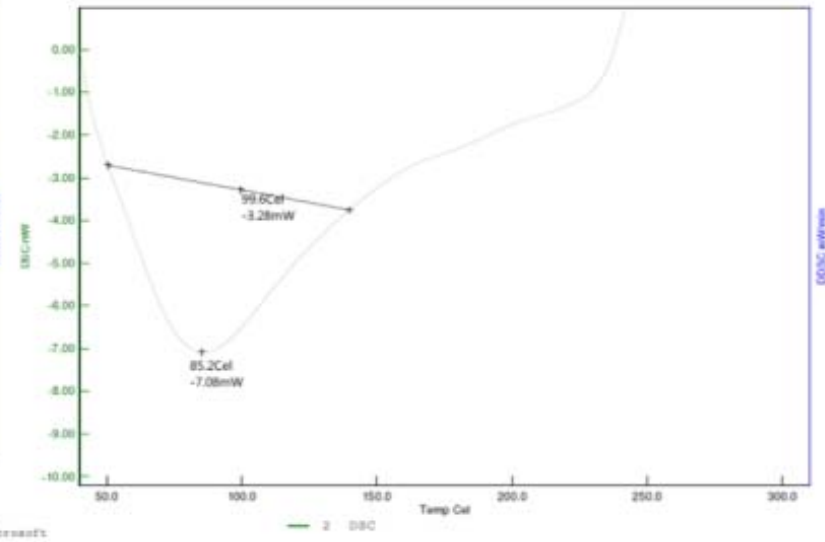

CE

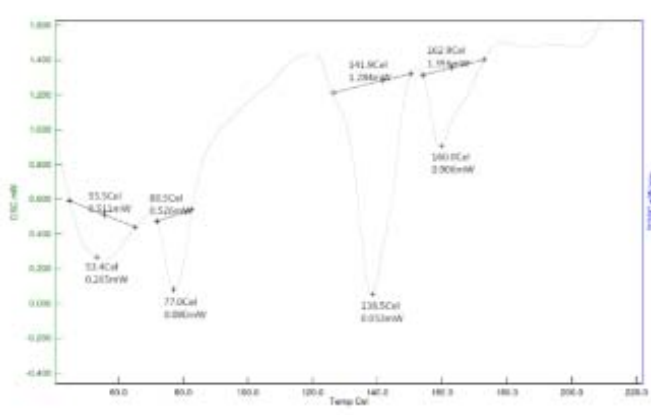

F7

Fig. 3: DSC thermograms of Glipizide, CE, HPMC, and F7
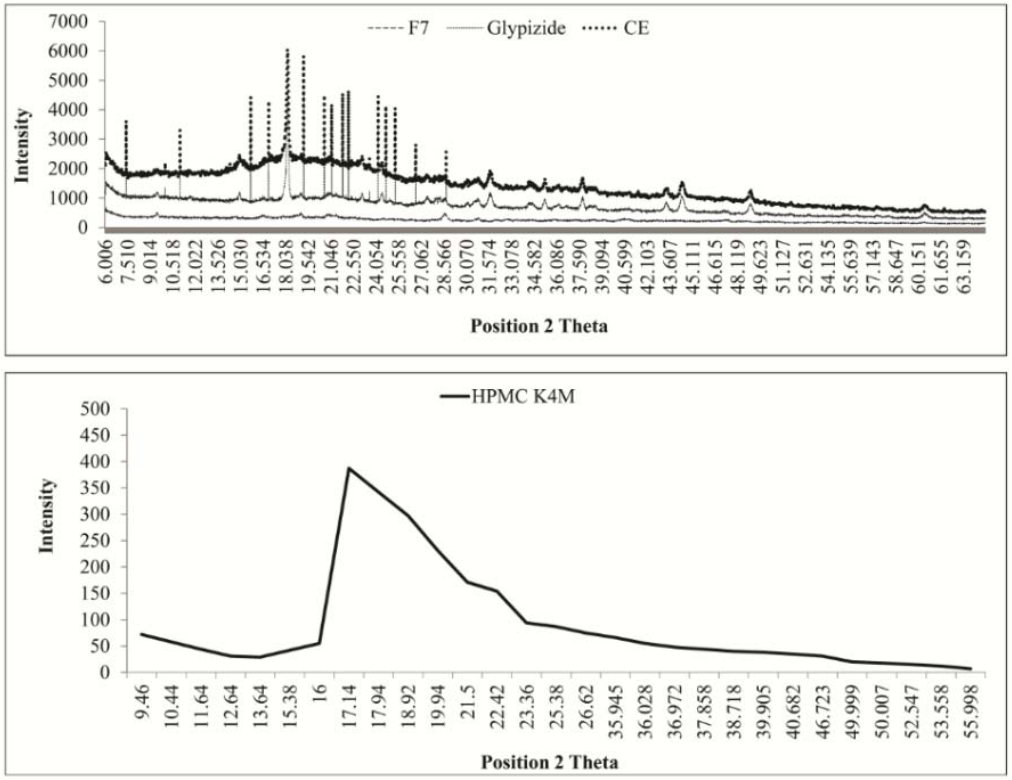

Fig. 4: X-ray diffraction patterns of Glipizide, CE, HPMC, and F7 


\section{XRD study}

XRD analysis patterns of the Glipizide, CE, HPMC, and F7 has been illustrated in fig. 4. Glipizide exhibited various sharp peaks; it is signifying the crystalline nature of Glipizide; subsequently formulations F7 have revealed straight line and absence of characteristic peaks indicates. Nevertheless, formulation F7 has exhibited lots of very sharp characteristic peaks. This may be owing to the molecular transformation of polymers for the duration of compression, or sodium bicarbonate might be progressively converted into anhydrous sodium bicarbonate with increased temperature [45].

\section{DISCUSSION}

The main objective of the present study was to develop a sustained release, mucoadhesive, and floating tablets of Glipizide for exploring $\mathrm{CE}$, and FG as the potential buoyancy enhancing agents, and mucoadhesive agents. The swellable, immediately float, fast gastric emptying, long reside in the stomach, and sustained-release tablets of Glipizide was successfully developed by direct compression technique [40]. Results of the thickness showed that the tablets maintained uniform dimensions during manufacturing [15]. The weight variation test results found to be acceptable limits. As per the IP specifications for tablets more than $80 \mathrm{mg}$ and less than 250 $\mathrm{mg}, \pm 7.5 \%$ is acceptable. These differences may be attributed to the deviation in particle size of powders [48]. The results of the hardness test revealed that the tablets having sufficient crush strength during transportation. Results of the friability study demonstrating that the developed formulations could withstand the mechanical shock during transportation [49]. The results of drug content indicative of the powder mixtures employed were freeflowing, subsequently die cavity was uniformly filled during compression; hence uniform weight tablets obtained. The FLT and buoyancy duration time is the most important parameters for the development of successful GRDDS. The faster onset of action and faster duration of the floating tablet can prevent the movement of dosage form from the stomach to intestine and gives the local drug absorption [32, 50-51]. Therefore, buoyancy duration time for F6 and F7 formulations was found to be $20 \mathrm{~h}$; it might be ascribed to the synergistic property like swelling and buoyancy behavior of CE-GG (F6) and CE-HPMC K4M(F7) (52). Therefore F8 and F9 discovered buoyancy duration time was $18 \mathrm{~h}$. It may be attributed to the acceptable swelling property and hydrophilic nature of FG $[53,54]$.

The swelling properties of a tablet are the important parameter to retain the tablet in the pyloric sphincter. To achieve the goal of prolonged gastric retention, the tablets can swell more than $2 \mathrm{~cm}$ in size to prevent the passage of tablets through the pyloric sphincter [55]. Glipizide-loaded floating tablets made up of the matrix-forming agents; they might form a layer of gel around the tablet core, when they come in contact with the fluid. Due to the viscous gel layer of the tablet, the liquid medium incapable to come in contact with the tablet core and reduces the diffusion process, followed by drug release from a tablet may be decreased. The viscous gel layer of the tablet al. so affects the floating duration and swelling properties of a tablet [47]. The results of SI study revealed that tablets which have long buoyant duration time and shortest lag time caused low SI; subsequently, tablets with the shortest floating lag time and prolonged floating duration exhibited moderately high SI. From the results of the in vitro drug dissolution study data, it was confirmed that in combination of CE and FG with GG and HPMC K4M (F6-F9) has revealed the sustained release characteristics. Finally, it was an unambiguous that the natural macromolecules can be prominently potential for the development of a floating sustained release drug delivery system. The various mathematical models are available, among that Higuchi square root model is major one used to fit the kinetics of drug release from the tablets [56]. The formulation from F1-F6 and F8 showed Non-Fickian or anomalous diffusion illustrations due to the relaxation of the polymeric groups, and affects the drug releases. These hydrophilic glassy polymers when placed in media they may be swelling and show anomalous-diffusion $[43,44]$. The hydrophilic glassy polymers swell in contact with water and become rubbery, then show anomalous-diffusion as a result of the rearrangement of macromolecular chains, whereas formulation F4 and F9 have been exhibited the Quassi-diffusion mechanism. Though, F7 revealed Anomalous diffusion or non fickian-diffusion. The formulation containing both GG and FG (F8) demonstrated higher bioadhesiveness strength than other formulations. It could be owing to the high molecular weight and strong hydrogen bond-forming groups between GG and FG [46]. The formulation F7 unveiled very high In vitro bioadhesiveness strength and detachment bioadhesive force as compared to other formulations. F7 revealed higher adhesion and adhesive force as compared to F6, F8, and F9. It might be a combination of CE and HPMC exhibited mucin interaction strongly. Typically, good wetting and swelling properties should correlate to good mucoadhesion, however only up to a certain point; polymer swelling behavior is essential for the exposure of the bioadhesive sites for the formation of strong hydrogen bonding and important character for uniform and sustained release of the drug and effective mucoadhesion [36, 37]. Therefore, based on the results of the In vitro buoyancy, in vitro drug release, in vitro bioadhesive studies and cost-effectiveness of CE compared to FG; F7 has been selected as the final formulation. FTIR data demonstrated that CE could be a good bioadhesiveness agent by forming a hydrogen bond between hydroxyl and carboxyl groups. DSC study results exhibited that the developed formulation was converted into amorphous form and absence of drug excipient interactions [47]. The XRD of formulations F7 discovered the straight line and the absence of characteristic peaks indicates the amorphous nature.

\section{CONCLUSION}

The promising, novel optimized, swellable, mucoadhesive and sustained release, buoyant tablets of Glipizide successfully developed by using CE, FG, GG and HPMC K4M, and in combination of GG+CE (F6), CE+HPMC K4M(F7), GG+FG (F8), and HPMCK4M+FG (F9). The thickness, weight variation, hardness, friability, and drug content uniformity evaluation results found satisfactory. The in vitro buoyancy study results revealed the prolonged buoyant duration (12-18 h). The results of the SI studies for formulations F1 to F9 have been shown the very good swelling properties. Thus, SI study results overlapped with results of the In vitro buoyancy studies. The In vitro drug release studies of formulations F1-F2, and F5 have revealed $100 \%$ drug release for a period of $4 \mathrm{~h}$, although; F6-F9 exhibited $100 \%$ drug release in the period of $12 \mathrm{~h}$. The formulations from F1-F6 and F8 exhibited in first-order release kinetics; whereas; the formulations F7 and F9 have been exhibited in Higuchi's model. Among the various mathematical models; Higuchi model is the best fit model used in the kinetics of drug release. Moreover; In vitro mucoadhesive study results confirmed the good adhesive to GI mucosa and swelling of the tablet to prevent the movement of tablets from the stomach to intestine through the pyloric sphincter. FTIR and DSC study revealed the absence of drug excipient interactions, and XRD study exhibited the final formulation (F7) is amorphous. Therefore, the natural macromolecules (CE) may be potential, effective, safe carriers for improving buoyancy and novel hydrocolloids for the development of mucoadhesive and sustained release floating tablets of Glipizide. However, the results of the F7 and F9 formulations were revealed mostly comparable in all evaluation data. But, CE could be cheap as compared to FG. Hence, $\mathrm{CE}$ might be the best potential natural macromolecule for the replacement of synthetic polymers.

\section{FUNDING}

This work was supported by Science and Engineering Research Board, Department of Science and Technology (DST-SERB), Government of India, New Delhi (Project File No. ECR/2017/000175) to Dr. Dalapathi Gugulothu

\section{ACKNOWLEDGMENT}

The authors are grateful to Balaji institute of Pharmaceutical Sciences for providing Infrastructure facilities for carrying out this study.

\section{AUTHORS CONTRIBUTIONS}

Dr. Dalapathi Gugulothu designed the work. Suraj Kuamr Choudhary performed experiments and collected data. Both authors analyzed 
the data and interpreted the results and wrote the manuscript. Both authors have read and approved the final manuscript.

\section{CONFLICT OF INTERESTS}

The authors declare that there is no conflict of interest.

\section{REFERENCES}

1. Singh A, Kumar N, Langyan M, Ahuja M. Evaluation of Mimosa pudica seed mucilage as sustained-release excipient. AAPS PharmSciTech 2009;10:1121-7.

2. Vipul D, Prajapati GJG, Naresh G, Randeria NP. Pharmaceutical applications of various natural gums, mucilages and their modified forms. Carbohydr Polym 2013;92:1685-99.

3. Nayak AK, Pal DK, Santra K. Development of calcium pectinatetamarind seed polysaccharide mucoadhesive beads containing metformin HCl. Carbohydr Polym 2014;101:223-30.

4. Nayak AK, Pal DK, Pradhan JP, Hasnain MS. Fenugreek seed mucilage-alginate mucoadhesive beads of metformin $\mathrm{HCl}$ : Design, optimization and evaluation. Int J Biol Macromol 2013;54:144-54.

5. Nerkar PP, Gattani S. In vivo, in vitro evaluation of linseed mucilage based buccal mucoadhesive microspheres of venlafaxine. Drug Delivery 2011;18:111-21.

6. Bahadur S, Sahu UK, Sahu D, Sahu G, Roy A. Review on natural gums and mucilage and their application as excipient. Int J Appl Pharm 2017;5:13-21.

7. Kharwade RS, More SM, Mahajan UN. Formulation and evaluation of gastroretentive floating tablet using hibiscus rosa-sinensis mucilage. Asian J Pharm Clin Res 217;10:444-8.

8. Shah V, Patel R. Studies on mucilage from hibuscus rosasinensis linn as oral disintegrant. Int J Appl Pharm 2010;2:18-21.

9. Deore UV, Mahajan HS. Isolation and characterization of natural polysaccharide from Cassia Obtustifolia seed mucilage as film forming material for drug delivery. Int J Biol Macromol 2018;115:1071-8.

10. Reddy DD, Bharathi V, Swarnalatha D, Gopinath C. Formulation and characterization of diltiazem hydrochloride matrix tablets by using natural polymers. Int J Pharm Sci Res 2010;9:283-91.

11. Prajapati VD, Jani GK, Moradiya NG, Randeria NP, Maheriya PM, Nagar BJ. Locust bean gum in the development of sustained release mucoadhesive macromolecules of aceclofenac. Carbohydr Polym 2014;113:138-48.

12. Dwivedi C, Rao S, Roy A, Saraf Kulsum U, Verma NS. Formulation and characterization of metformin hydrochloride sustained release matrix tablet containing Cassia Tora mucilage. J Drug Delivery Ther 2017;7:66-75.

13. Hadad S, Goli SAH. Fabrication and characterization of electrospun nanofibers using flaxseed (Linumusitatissimum) mucilage. Int J Biol Macromol 2018;114:408-14.

14. Liang $\mathrm{H}$, Ye $\mathrm{T}$, Zhou B, Li J. Fabrication of gastric floating controlled release tablet based on konjacglucomannan. Food Res Int 2015;72:47-53.

15. Rimi D, Bandyopadhyay AK. Development of a new nasal drug delivery system of diazepam with natural mucoadhesive agent from Trigonellafoenum-graecum L. J Sci Ind Res 2005;64:973-7.

16. Maiti S, Dey P, Banik A, Sa B, Ray S, Kaity S. Tailoring of locust bean gum and development of hydrogel beads for controlled oral delivery of glipizide. Drug Delivery 2010;17:288-300.

17. Pandey M, Maher M, Semalty M, Semalty A. Natural macromolecules in the development of safe and effective gastroretentive floating microparticles of metformin hydrochloride. Nat Prod J 2016;6:62-72.

18. Hirtz J. The GIT absorption of drugs in man: A review of current concepts and methods of investigation. Br J Clin Pharmacol 1985;19:77S-83S.

19. Rashmitha V, Madhusudan Rao Y, Pavani S. Formulation and evaluation of fenoverine floating tablets. Asian J Pharm Clin Res 2021;14:175-80.

20. Streubel A, Siepmann J, Bodmeier R. Gastroretentive drug delivery systems. Expert Opin Drug Delivery 2006;3:217-33.

21. Chitnis VS, Malshe VS, Lalla JK. Bioadhesive polymers synthesis, evaluation and application in controlled release tablets. Drug Dev Ind Pharm 1991;17:879-92.

22. Chueh HR, Zia H, Rhodes CT. Optimization of sotalol floating and bioadhesive extended release tablet formulations. Drug Dev Ind Pharm 1995;21:1725-47.
23. Arora G, Malik K, Singh I, Arora S, Rana V. Formulation and evaluation of controlled release matrix mucoadhesive tablets of domperidone using Salvia plebeian gum. J Adv Pharm Technol Res 2011:2:163-9.

24. Choudhary PD, Pawar HA. Recently Investigated Natural gums and mucilages as pharmaceutical excipients: an overview. J Pharm 2014. https://doi.org/10.1155/2014/204849

25. Chowdary KPR, Srinivas YR. Design and in vitro evaluation of mucoadhesive controlled release oral tablet of glipizide. Indian J Pharm 2003;65:592-9.

26. Thombre AG, Denoto AR, Gibbes DC. Delivery of glipizide from asymmetric membrane capsules using encapsulated excepients. J Controlled Release 1999;60:333-41.

27. Rendell $M$. The role of sulphonylureas in the management of type 2 diabetes mellitus. Drugs 2004;64:1339-58.

28. Fassihi R, Jamzad S. Development of a controlled release low dose class II drug-glipizide. Int J Pharm 2006;31:24-32.

29. Saharan P, Bahmani K, Saharan SP. Preparation, optimization and in vitro evaluation of glipizide nanoparticles integrated with eudragit RS-100. Pharm Nanotechnol 2019;7:72-85.

30. Hesieh SH, Lin JD, Chang HY, Ho C, Liou LJ. Sustained release versus immediate release glipizide for the treatment of diabetes mellitus in Chinese patients: a randomized, double blind, double dummy, parallel group, 12-week clinical study. Clin Ther 2006;28:1318-26.

31. Chen RN, Ho H, Yu CY, Sheu MT. Development of swelling/floating gastroretentive drug delivery system based on a combination of hydroxyethyl cellulose and sodium carboxymethyl cellulose for losartan and its clinical relevance in healthy volunteers with CYP2C9 polymorphism. Eur J Pharm Sci 2010;39:82-9.

32. Varshosaz J, Tavakoli N, Roozbahani F. Formulation and in vitro characterization of ciprofloxacin floating and bioadhesive extended-release tablets. Drug Delivery 2006;13:277-85.

33. Qin C, Wu M, Xu S, Wang X, Wenxing Shi W, Dong Y. Design and optimization of gastro-floating sustained-release tablet of pregabalin: In vitro and in vivo evaluation. Int J Pharm 2018:545:37-44.

34. Slima SB, Ktari N, Trabelsi I, Moussa H, Makni I, Salah RB. Purification, characterization and antioxidant properties of a novel polysaccharide extracted from Sorghum bicolor (L.) seeds in sausage. Int J Biol Macromol 2008;106:168-78.

35. Paul Y, Kumar M, Singh B. Formulation, evaluation and study of effect of hydrophilic polymers on release rate of cefixime floating tablets. Int J Pharma Bio Sci 2011:2:472-88.

36. Alopaeus JF, Hellfritzsch M, Gutowski T, Scherlie R, Almeida R, Sarmento B, et al. Mucoadhesive buccal films based on a graft co-polymer-a mucin-retentive hydrogel scaffold. Eur J Pharm Sci 2020;152. https://doi.org/10.1016/j.ejps.2019.105142.

37. Figueiras A, Pais AACC, Veiga FJB. A comprehensive development strategy in buccal drug delivery. AAPS PharmSciTech 2010;11:1703-12.

38. Bhalekar MR, Bargaj RV, Upadhaya PG, Madgulkar A, Kshrisagar S. Formulation of mucoadhesive gastric retentive drug delivery using thiolatedxyloglucan. Carbohydr Polym 2016;136:537-42.

39. Razavi M, Nyamathulla S, Karimian H, Noordin MI. Novel swellable polymer of orchidaceae family for gastroretentive drug delivery of famotidine. Drug Design Dev Ther 2014;8:1315-29.

40. Belgamwar VS, Surana SJ. Floating bioadhesive drug delivery system using novel effervescent agents. Asian J Pharm 2009;3:156-60.

41. Pawar J, Dhavale R. Development and evaluation of gastroretentive floating tablets of an antidepressant drug by thermoplastic granulation technique. Beni-Suef Univ J Basi Appl Sci 2014;3:122-32.

42. Bravo SA. In vitro studies of diclofenac sodium controlledrelease from biopolymeric hydrophilic matrices. J Pharm Pharm Sci 2002;5:213-9.

43. Ghasemlou M, Khodaiyan F, Oromiehie A. The effect of plasticizers on mechanical properties and water vapor permeability of gelatin-based edible films containing clay nanoparticles. Carbohydr Polym 2011;84:477-83.

44. Peppas NA. Analysis of fickian and non-fickian drug release from polymers. Pharm Acta Helv 1985;60:110-1. 
45. Muller Lissner SA, Blum AL. The effect of specific gravity and eating on gastric emptying of slow-release capsules. New Engl J Med 1981;304:1365-6.

46. Sharma N, Sharma A, Nishad DK, Khanna K, Sharma BG, Kakkar $\mathrm{D}$, et al. Development and gamma scintigraphy study of Trigonellafoenum-graecum (Fenugreek) polysaccharide-based colon tablet. AAPS PharmSciTech 2018;19:2564-71.

47. Essa EA, Elkot FE Zin, Eldin EE. Development and evaluation of glibenclamide floating tablet with optimum release. J Drug Delivery Sci Technol 2015;27:28-36.

48. Eichie FE, Kudehinbu AO. Effect of particle size of granules on some mechanical properties of paracetamol tablets. Afr J Biotechnol 2009;8:5913-6.

49. Senjoti FG, Mahmood S, Jaffr JM, Mandal UK. Design and in vitro evaluation of sustained release floating tablets of metformin $\mathrm{HCl}$ based on effervescence and swelling. Iran J Pharm Res 2016;15:53-70

50. Savic IM, Nikolic K, Nikolic G, Zhu C, Cao H, Zhou J, et al. Application of mathematical modeling for the development and optimization formulation with bioactive copper complex. Drug Dev Ind Pharm 2013;39:1-7.
51. Yin L, Qin C, Chen K, Zhu C, Cao H, Zhou J, et al. Gastro-floating tablets of cephalexin: preparation and in vitro/in vivo evaluation. Int J Pharm 2013;452:241-8.

52. Nabarawi MAE, Teaima MH, Monem RAAE, El Nabarawy NA, Gaber DA. Formulation, release characteristics, and bioavailability study of gastroretentive floating matrix tablet and floating raft system of mebeverine HCl. Drug Des Dev Ther 2017;11:1081-93.

53. Tekade BW, Jadhao UT, Patil SG, Patil VR. Formulation and in vitro evaluation of floating tablets of cefpodoxime proxetil. Int $\mathrm{J}$ Curr Pharm Res 2017;9:18-22.

54. Auriemma G, Cerciello A, Sansone F, Pinto A, Morello S, Rita RP. Polysaccharides based gastroretentive system to sustain piroxicam release: Development and in vivo prolonged antiinflammatory effect. J Controlled Release 2006;115:121-9.

55. Chen YC, Ho HO, Lee TY, Sheu MT. Physical characterizations and sustained release profiling of gastroretentive drug delivery systems with improved floating and swelling capabilities. Int J Pharm 2013;441:162-9.

56. Pendekal MS, Tegginamat PK. Formulation and evaluation of a bioadhesive patch for buccal delivery of tizanidine. Acta Pharm Sinica B 2012;2:318-24. 